\title{
ANALYSIS OF THE KINEMATICS AND COMPLIANCE OF A PASSIVE SUSPENSION SYSTEM USING ADAMS CAR
}

\author{
N. Ikhsan ${ }^{1}$, R. Ramli ${ }^{2}$ and A. Alias ${ }^{3}$ \\ ${ }^{1}$ Faculty of Mechanical Engineering, UiTM Shah Alam, \\ 40450 Shah Alam, Selangor \\ Email: nurzaki@salam.uitm.edu.my \\ Phone: +60192819252, Fax: +60355435160 \\ ${ }^{2}$ Department of Mechanical Engineering, Faculty of Engineering, \\ University of Malaya, 50603 Kuala Lumpur \\ ${ }^{3}$ R\&D Department, Perusahaan Otomobil National
}

\begin{abstract}
The experimental approach is usually used as the way to develop or modify a suspension system to obtain maximum ride comfort and handling characteristics. This approach is a time-consuming process, costly, and may not guarantee the optimum solution. Thus, to avoid this, a virtual vehicle suspension system is necessary. In this paper, a half-car body of an actual suspension system based on the PROTON WRM 44 P0-34 was modeled and simulated. In total, 10 components comprised each front McPherson strut and rear multilink suspension consisting of different joint types and a number of degrees of freedom. The model was developed by defining the location of the hard point or coordinate before specifying the component characteristics and joint type. The completed suspension model was simulated using the vertical parallel and vertical oppose movement test, the same tests conducted with the actual experimental parameter setup. The kinematics and compliance $(\mathrm{K} \& \mathrm{C})$ of the simulation is compared with the experimental data to verify the suspension model. The outcome from the simulation showed a verified virtual suspension system model with a very minimum percentage of error and different characteristics of the static performance of the suspension system when subjected to the test as explained further in the paper.
\end{abstract}

Keywords: Suspension modeling; McPherson suspension, multilink suspension, vertical parallel and oppose wheel movement test

\section{INTRODUCTION}

Nowadays, the automotive industry is one of the fastest growing industries around the world [1]. In order to improve the handling and riding comfort of a vehicle, the suspension system design is the main factor as it is used to support the load, and protect the passengers by absorbing the shock and vibration [2]. Overall, the suspension system consists of dampers, springs, arms, knuckles and anti-roll bars as the main components and bushings, bearings and fasteners as the support components [3-7]. It is crucial for the suspension setup and design that modifications are made correctly at the start by considering the entire performance and vehicle capability [8]. The purpose of this study is to generate and simulate a fully working virtual suspension model of the actual PROTON WRM 44 P0-34 McPherson strut type for the front and the multilink type for the rear suspension systems. Generating the virtual suspension system model is 
basically to reduce the number of result errors [8]. Traditionally, in order to develop or modify the components of a suspension system, the testing method using a suspension test rig is employed to ascertain the characteristics. Basically, this approach is time consuming, costly, requires workmanship and might include errors due to the human factor, thus may not guarantee the optimum solution. However, the suspension system has to be proven to be correctly modeled. One of the solutions is to use the verification method. Verification can be achieved by comparing the simulated result with the experimental result or mathematical model [3]. In this paper, only the simulated result will be compared with the experimental result. Both the simulated and experimental results only consider the value of the toe change, camber change and caster change when subjected to the vertical parallel movement test and vertical oppose movement test, replicating the same experimental setup used by PROTON. In the following subsection, the methodology adopted for this study is discussed briefly including modeling of the suspension system and the simulation process. Finally, detailed discussions on the result and the conclusion are presented.

\section{METHODOLOGY}

The process for this study involved several important steps, starting with the modeling of a front half and rear half suspension system using the MSC/ADAMS car, employing the movement simulation analysis test, and generating the kinematics and compliance $(\mathrm{K} \& \mathrm{C})$ data for selected outputs for verification purposes.

\section{Suspension Modeling}

The multi-body model of a suspension system is based on the actual PROTON passenger car suspension system, the PROTON WRM 44 P0-34. As mentioned before, McPherson struts will be used for the front suspension system while multilink suspension will be used for the rear, as shown in Figure 1. In order to replicate the actual suspension system, the model must be built using the same parameters as the actual suspension, such as the hard-point geometry, damper profiles (Figure 2), spring stiffness, anti-roll bar stiffness, material selection for the components, joining type and orientation as well as bushing properties [9]. In total, 10 component hard point in the $\mathrm{x}$, $\mathrm{y}, \mathrm{z}$ directions for both suspension models with specific joining types and orientations were found. The modeling stage starts by generating the suspension model template. This stage is important since it will determine the accuracy and working behavior of the suspension as an actual suspension. Once the template is made, it must be saved as a subsystem. At this point, not as many parameters can be changed as can be changed at the template stage. Four subsystems were used for this study: the McPherson suspension and the front anti-roll bar for the front suspension model and the multilink suspension and the rear-anti-roll bar for rear suspension model. Finally, the subsystems are assembled as one working suspension system assembly ready for simulation. Note that only complete assembly systems can be analyzed and simulated to generate the data results [10]. Tables 1 and 2 show the individual suspension component positions and topology modeling for each suspension and the connectivity of each component with other components via joint type as well as the number of degrees of freedom. 


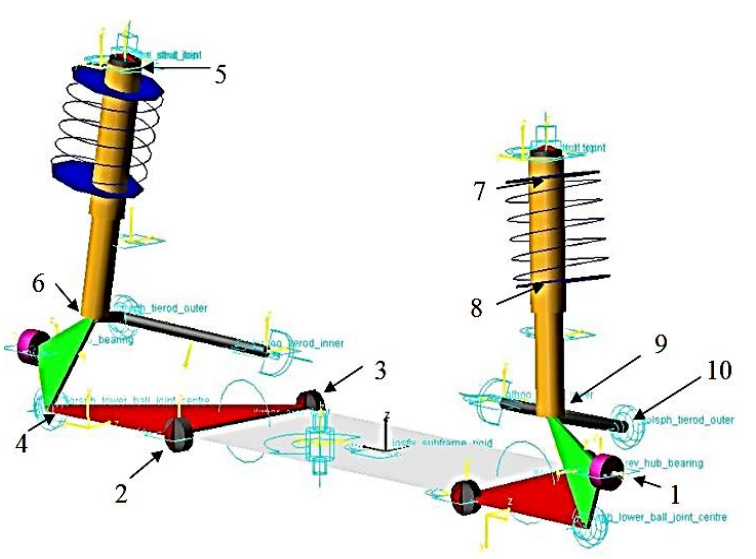

(a)

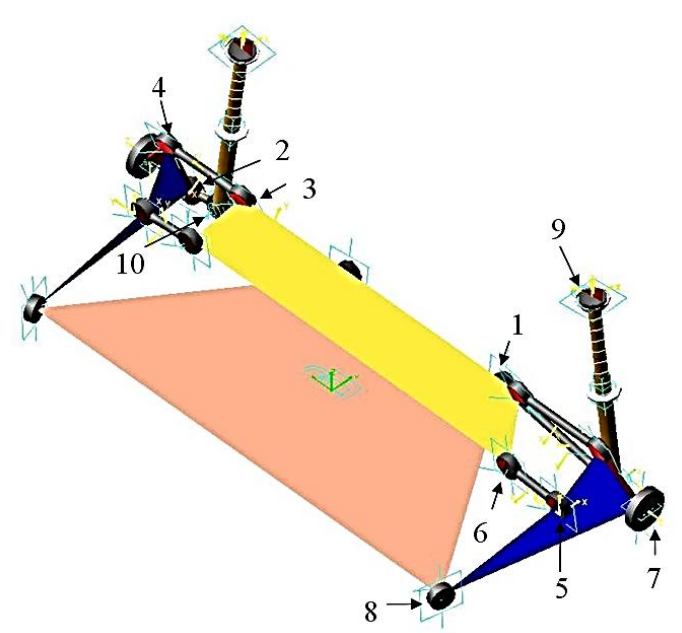

(b)

Figure 1. Suspension template model generated on MSC/ADAMS Car;

(a) McPherson strut suspension (b) Multilink suspension.

Table 1. Topology modeling for McPherson strut suspension system.

\begin{tabular}{cllll}
\hline $\begin{array}{c}\text { Comp. } \\
\text { No. }\end{array}$ & Components & Connected Part & Joint & $\begin{array}{c}\text { Degree of } \\
\text { Freedom }\end{array}$ \\
\hline 1 & Wheel Center & Wheel Carrier & Revolution Joint & 1 Rotation \\
2 & Lower Arm - Front & Wral \\
3 & Lower Arm - Rear & Body Sub-frame & Parallel Axes Joint & 1 Translational, \\
4 & Lower Arm - & Body Sub-frame & Parallel Axes Joint & 1 Translational, \\
5 & Outer & Wheel Carrier & Spherical Joint & 3 Rotation \\
6 & Strut-Top & Ground & Orientation Joint & 3 Translational \\
7 & Strut-Lower & Wheel Carrier & Translational Joint & 1 Translational \\
8 & Spring center- & Strut & Translational joint & 1 Translational \\
9 & upper & Strut & Translational joint & 1 Translational \\
10 & Spring center- & Ground & Hooke Joint & 2 Rotation \\
& lower Tierod-Inner & Wheel Carrier & Spherical Joint & 3 Rotation \\
& Tierod-Outer & & & \\
\hline
\end{tabular}

\section{Suspension Simulation}

The suspension model simulation test is conducted using a suspension test rig (Figure 3 (a) and (b)) [8]. The method and procedure is the same as the experimental setup. Two types of simulation test for both front and rear suspension systems were undertaken: the vertical parallel wheel movement test, where both the left and right wheels are subjected to simultaneously parallel movement in the same vertical direction with 30 steps of $40 \mathrm{~mm}$ bound and rebound travel value (total of $80 \mathrm{~mm}$ of wheel travel), and the vertical oppose wheel movement test where the wheel is subjected to simultaneously opposing movements for the same steps and travel value. 
Table 2. Topology modeling for multilink suspension system.

\begin{tabular}{lllll}
\hline $\begin{array}{l}\text { Comp. } \\
\text { No. }\end{array}$ & Components & Connected Part & Joint & Degree of Freedom \\
\hline 1 & Lower Arm - Inner & Ground & Parallel Axes & 1 Translational \\
2 & Lower Arm - Outer & Trailing Arm & Joint & 2 Translational, 3 Rotation \\
3 & Upper Arm - Inner & Ground & Inplane Joint & 1 Translational \\
4 & Upper Arm - Outer & Trailing Arm & Parallel Axes & 2 Translational, 3 Rotation \\
5 & Control Arm - Inner & Ground & Joint & 1 Translational \\
6 & Control Arm - Outer & Trailing Arm & Inplane Joint & 2 Translational, 3 Rotation \\
7 & Wheel Center & Wheel Carrier & Parallel Axes & 1 Rotation \\
8 & Trailing Arm & Ground & Joint & 2 Translational, 3 Rotation \\
9 & Strut-Top & Ground & Inplane Joint & 1 Translational, 3 Rotation \\
10 & Absorber To Lower & Ground & Revolute Joint & 1 Rotation \\
& Arm & & Inplane Joint & \\
& & Inline & \\
\hline
\end{tabular}

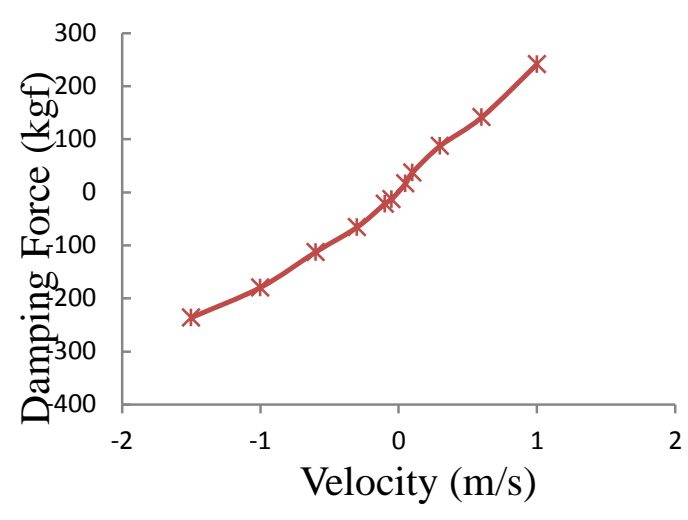

(a)

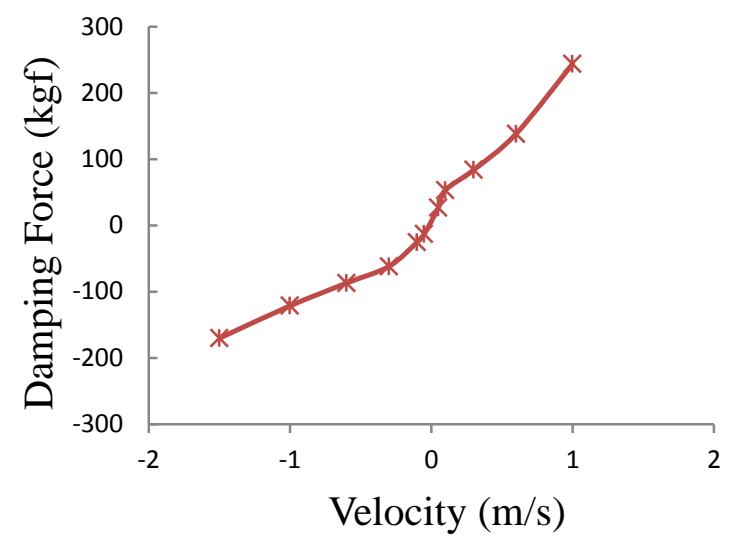

(b)

Figure 2. Damper profile (a) McPherson strut suspension (b) Multilink suspension.

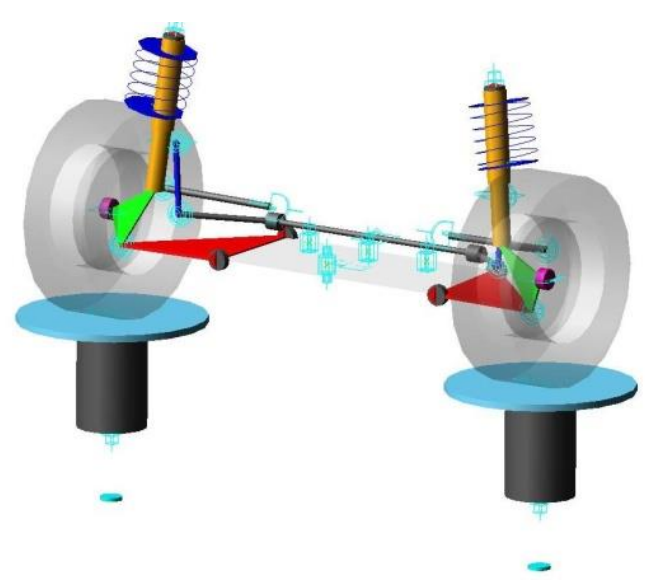

(a)

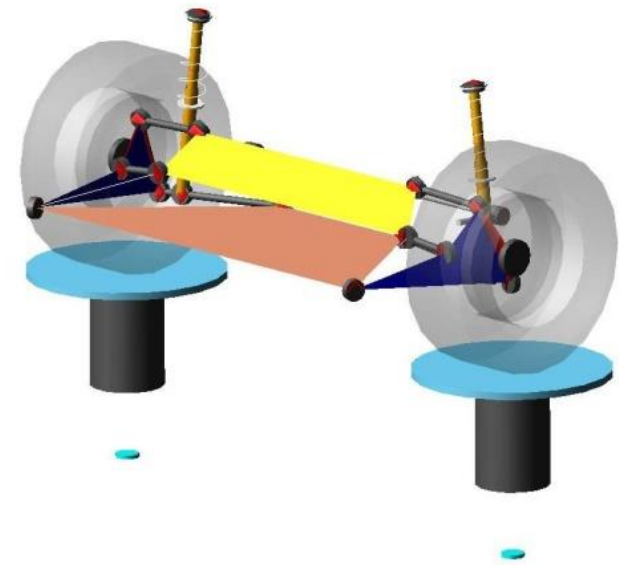

(b)

Figure 3. Complete suspension assembly simulation setup on MSC/ADAMS car test rig (a) McPherson strut suspension (b) Multilink suspension. 


\section{RESULTS AND DISCUSSION}

The simulation test generates a $\mathrm{K} \& \mathrm{C}$ data set. As mentioned before, only toe change, camber change and caster change values to the wheel movement are considered in comparison with the experimental result, since they give the significant effect of the overall $\mathrm{K} \& \mathrm{C}$ to the ride comfort and handling characteristics of the vehicle [11]. Thus, a total of 12 graphs were generated. At the start of generating the virtual suspension system model, the left and right sides of the suspension were set to be symmetrical having the same component properties to be simulated and tested. Thus, either the left or right data set can be used in the comparison with the experimental result after the simulation.

Figure 4 ((a)-(f)) shows graphs plotted for the McPherson and multilink suspension systems when subjected to the vertical parallel wheel movement test, while Figure 5((a)-(f)) show the vertical oppose wheel movement test.The McPherson suspension system shows a reduction in both toe and camber changes (Figure 4 (a)-(b), Figure 5(a)-(b)), from positive to negative values when subjected to both of the vertical wheel movement tests. This setup allows better vehicle handling and stability during cornering [11-13]. The different setup comes into the multilink suspension system by providing an increase in toe change while reducing the camber change when subjected to the same test as the McPherson suspension system (Figure 4(d)-(e), Figure 5(d)-(e)). The change in toe setting from the negative to the positive value for the multilink suspension system is basically to compensate for the front-wheel-drive's understeer since it induces a little oversteering during cornering. On the other hand, the negative camber of the multilink suspension system provides the same benefits as the McPherson suspension system.

The other purpose of virtual suspension modeling and analysis is to verify the simulated result with the experimental result. This clearly showed that all of the graphs in Figures 4 and 5 have the same tabulated pattern as the experimental results. However, some of the simulation data do not show $100 \%$ the same value when subjected to the same wheel travel as the experimental data. Thus, to analyze the results, the coefficient of determination for linear regression, $\mathrm{R}^{2}$, is used and the results are given in Table 3. Based on the table, the maximum $\mathrm{R}^{2}$ value at $9.47 \%$ was for the graph toe change for the front suspension when subjected to the vertical oppose wheel movement test (Figure 4(a)). The minimum percentage error was $0.29 \%$ on the caster change graph for the rear suspension when the vertical parallel wheel movement test was employed (Figure 5(f)). It is difficult to determine whether the simulated or experimental results are correct [3], but we could consider that human factor might have influenced the outcome of the experimental results (e.g. human error during the experiment or during component setup on the actual test rig). One of the other solutions and recommendations is to verify the simulation result with the mathematical model. 


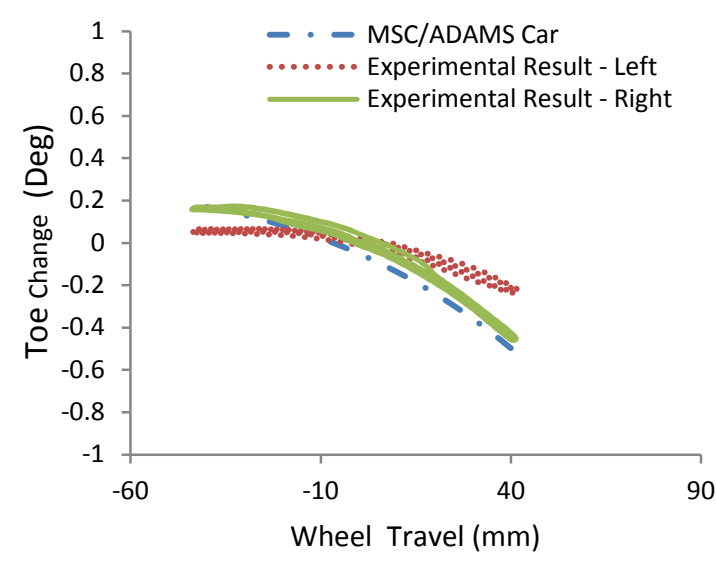

(a)

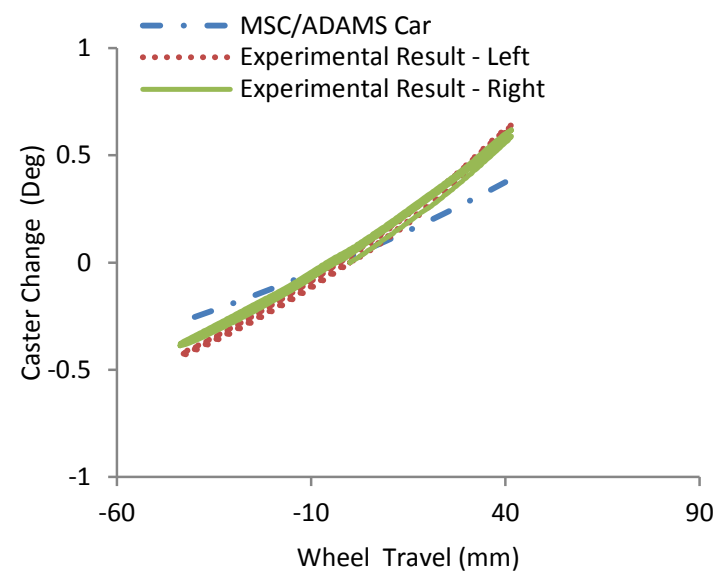

(c)

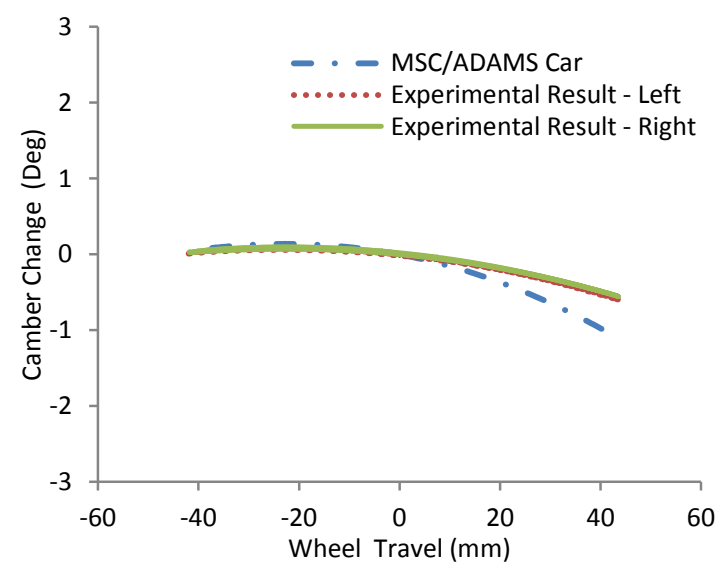

(e)

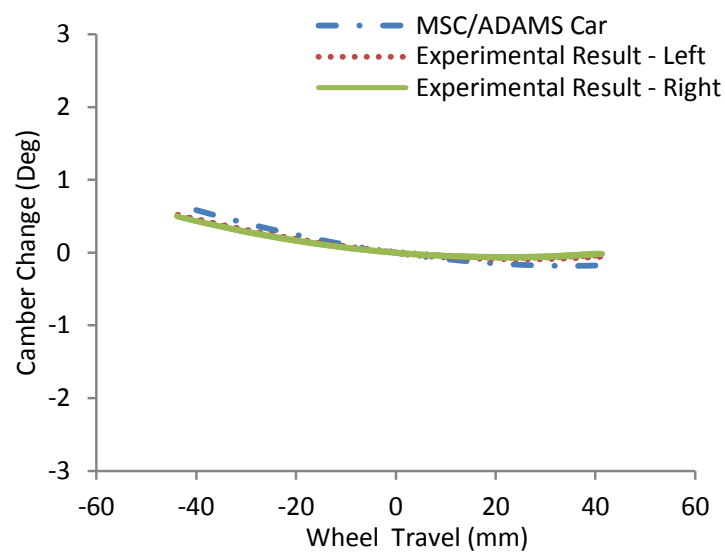

(b)

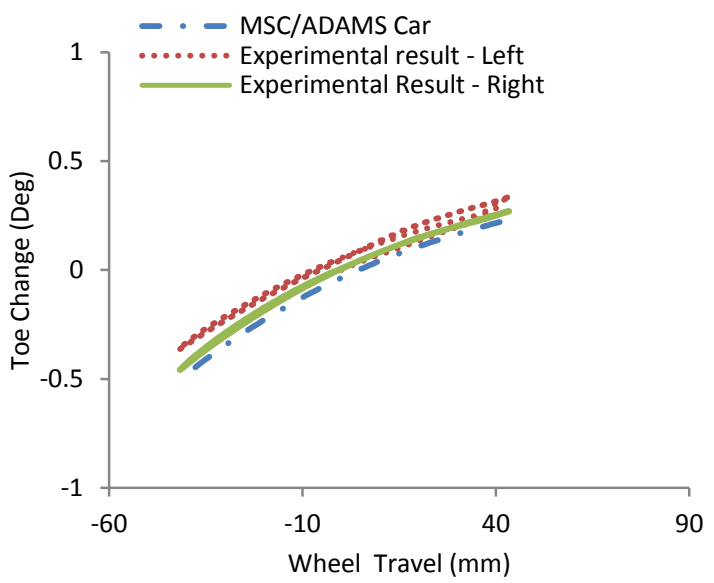

(d)

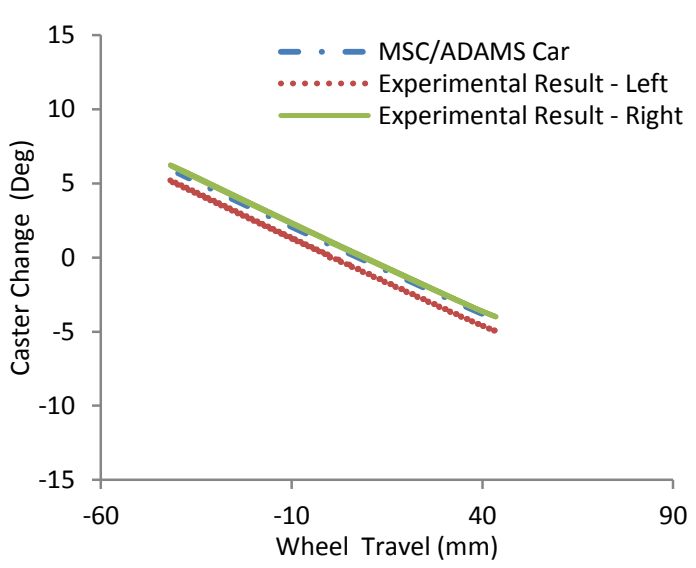

(f)

Figure 4. The left and right suspension systems for the vertical parallel wheel movement test comparison between the experimental and the simulation using MSC/ADAMS CAR for (a) front toe change; (b) front camber change; (c) front caster change; (d) rear toe change; (e) rear camber change and (f) rear caster change. 


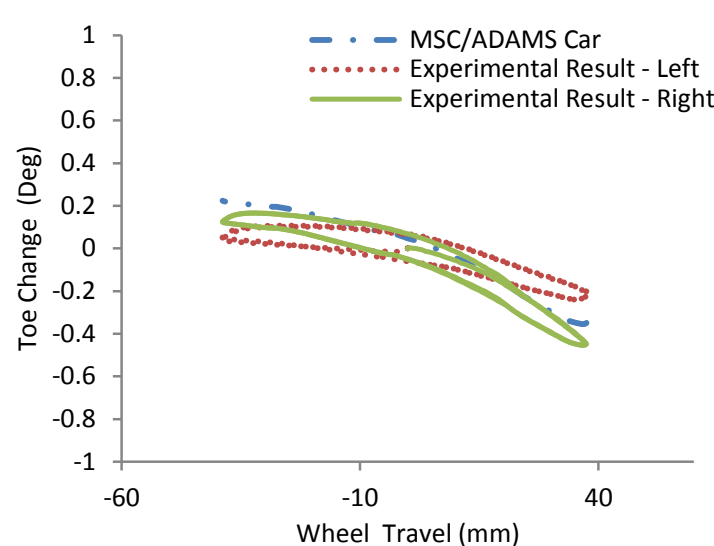

(a)

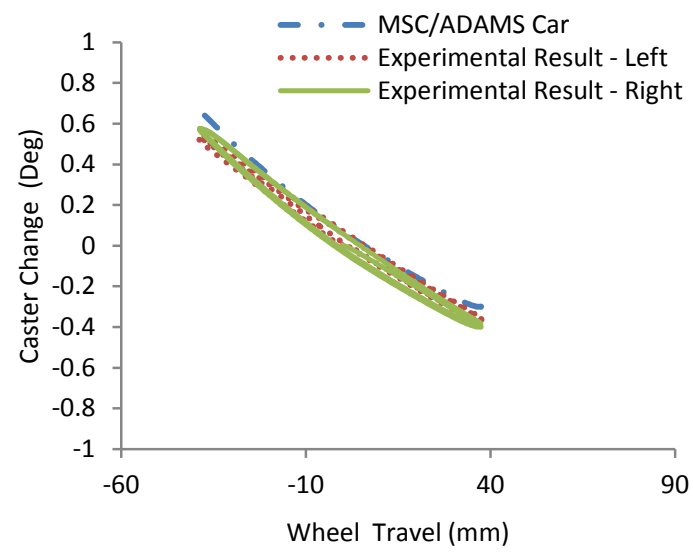

(c)

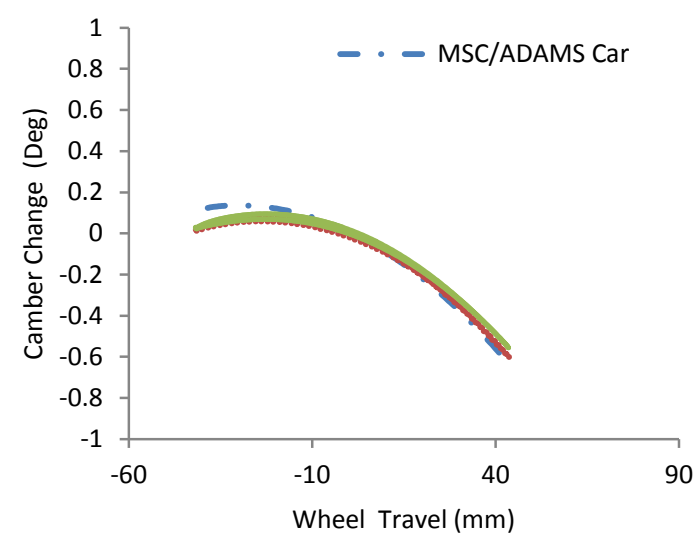

(e)

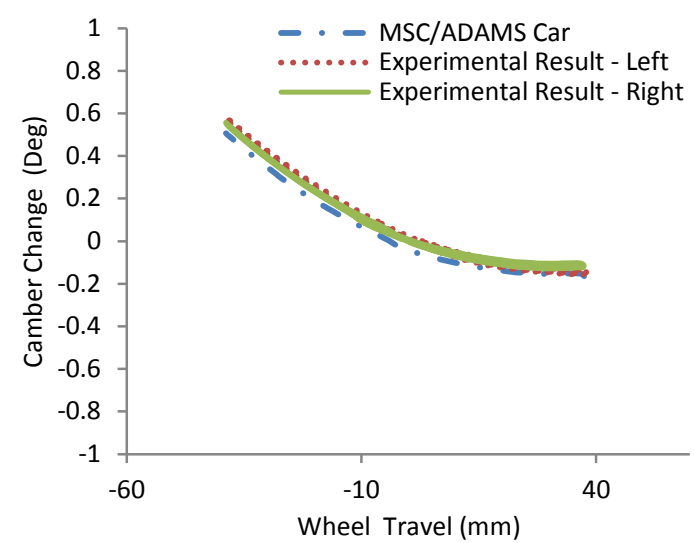

(b)

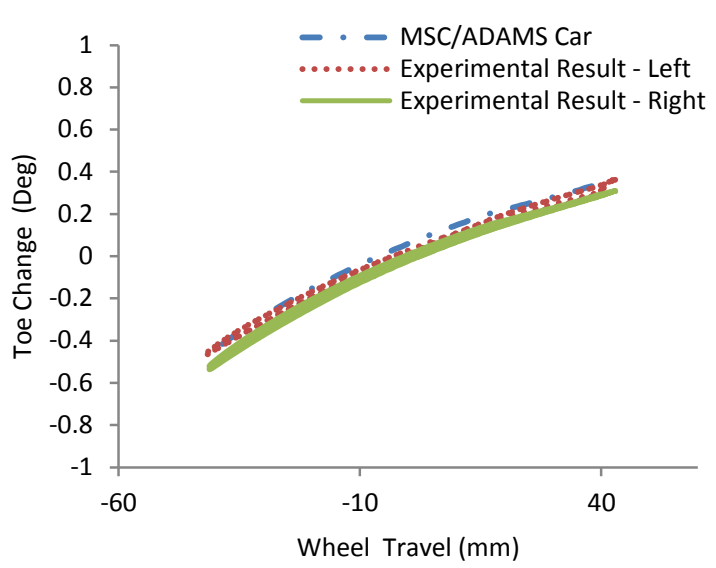

(d)

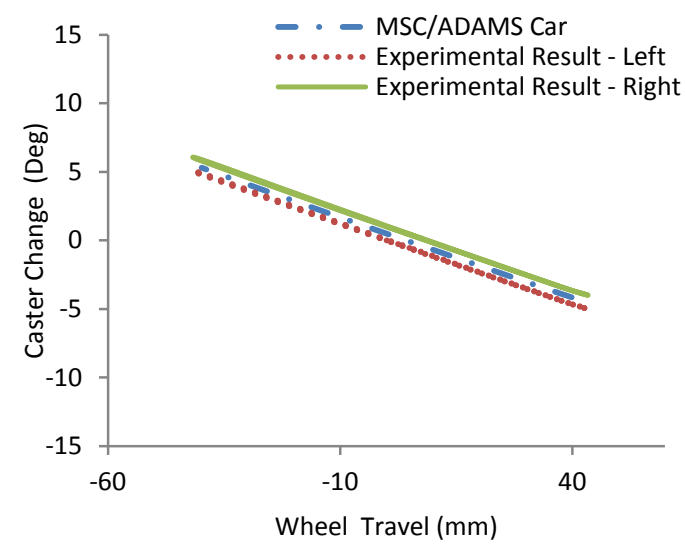

(f)

Figure 5. The left and right suspension systems for the vertical oppose wheel movement test comparison between the experimental and the simulation using MSC/ADAMS Car for (a) front toe change; (b) front camber change; (c) front caster change; (d) rear toe change; (e) rear camber change and (f) rear caster change. 
Table 3. Coefficient of determination, $\mathrm{R}^{2}$ for linear regression.

\begin{tabular}{|c|c|c|c|c|c|c|c|}
\hline & & \multicolumn{3}{|c|}{ Front } & \multicolumn{3}{|c|}{ Rear } \\
\hline & & Left & Right & $\begin{array}{l}\text { Exp. } \\
\text { Result }\end{array}$ & Left & Right & $\begin{array}{c}\text { Exp. } \\
\text { Result }\end{array}$ \\
\hline \multirow{6}{*}{$\begin{array}{l}\text { Vertical } \\
\text { parallel } \\
\text { movement } \\
\text { test } \\
\text { Vertical } \\
\text { Oppose } \\
\text { movement } \\
\text { test }\end{array}$} & Toe & 0.8511 & 0.9102 & 0.9299 & 0.9787 & 0.9736 & 0.9800 \\
\hline & Camber & 0.8962 & 0.8878 & 0.9251 & 0.8092 & 0.8052 & 0.8118 \\
\hline & Caster & 0.9872 & 0.989 & 0.9667 & 0.9997 & 0.9957 & 0.9968 \\
\hline & Toe & 0.8232 & 0.8662 & 0.9012 & 0.9775 & 0.9861 & 0.9787 \\
\hline & Camber & 0.8966 & 0.9177 & 0.8960 & 0.8092 & 0.8052 & 0.8511 \\
\hline & Caster & 0.9831 & 0.9910 & 0.9844 & 0.9998 & 0.9978 & 0.9968 \\
\hline
\end{tabular}

\section{CONCLUSIONS}

The virtual model of the front and rear suspension systems of the PROTON WRM 44 P0-34 was produced and simulated based on the same tests as for the actual suspension system. Both front and rear suspension models were compared and validated with the experimental results. Overall, even when the suspension is validated, the percentage error between the simulated and experimental results still needs to improve and be minimized. Further study has to be undertaken to solve this problem. Future work aims to conduct virtual full vehicle testing on the dynamic characteristics of the suspension system.

\section{ACKNOWLEDGEMENTS}

The authors gratefully acknowledge support from Perusahaan Otomobil Nasional Berhad [14] and Technofund Project, Ref No. TF0608C073.

\section{REFERENCES}

[1] Chikhale S, Deshm S. Comparative analysis of vehicle suspension system in matlab-simulink and MSc-ADAMS with the help of quarter-car model. International Journal of Innovations Research in Science. 2013;2:5452-9.

[2] Pathmasharma S, Suresh J, Viswanathan P, Subramanian R. Analysis of Passenger Car Suspension System Using Adams. International Journal of Science, Engineering and Technology Research. 2013;2:1186-93.

[3] Mántaras DA, Luque P, Vera C. Development and validation of a threedimensional kinematic model for the McPherson steering and suspension mechanisms. Mechanism and Machine Theory. 2004;39:603-19.

[4] Nagarkar MP, Vikhe GJ, Borole KR, Nandedkar VM. Active control of quarter car suspension system using linear quadratic regulator. International Journal of Automotive and Mechanical Engineering. 2011;3:364-72.

[5] Kamal M, Rahman MM, Sani MSM. Application of multibody simulation for fatigue life estimation. International Journal of Automotive and Mechanical Engineering. 2013;7:912-23. 
[6] Kamal M, Rahman MM. Finite Element-Based Fatigue Behaviour of Springs in Automobile Suspension. International Journal of Automotive and Mechanical Engineering. 2014;10:1910-9.

[7] Kamal M, Rahman MM, Rahman AG. Fatigue life evaluation of suspension knuckle using multibody simulation technique. Journal of Mechanical Engineering and Sciences. 2012;3:291-300.

[8] Ning X, Zhao C, Shen J. Dynamic analysis of car suspension using ADAMS/car for development of a software interface for optimization. Procedia Engineering. 2011;16:333-41.

[9] Attia H. Kinematic analysis of the multi-link five-point suspension system in point coordinates. KSME International Journal. 2003;17:1133-9.

[10] ADAMS M, Documentation C. MSc. Software Corporation. 2003.

[11] Milliken W, Milliken D. Race car vehicle dynamics. SAE International. ISBN 156098-526-9; 1995.

[12] Mitchell WC, Simons R, Sutherland T, Keena-Levin M. Suspension geometry: theory vs. K\&c measurement. SAE Technical Paper No. 2008-01-2948; 2008.

[13] Reimpell J, Stoll H, Betzler J. The automotive chassis: engineering principles: Butterworth-Heinemann; 2001.

[14] Proton PONSB. Vehicle drivability evaluation test procedure. 07-11-09/A/300004939. Shah Alam; 2009. 